\title{
LOW-FREQUENCY OSCILLATIONS IN HUMAN TIBIAL SOMATOSENSORY EVOKED POTENTIALS
}

\author{
Carlos Julio Tierra-Criollo ${ }^{1}$, Antonio Fernando Catelli Infantosi
}

\begin{abstract}
Oscillatory cerebral electric activity has been related to sensorial and perceptual-cognitive functions. The aim of this work is to investigate low frequency oscillations $(<300 \mathrm{~Hz})$, particularly within the gamma band $(30-110 \mathrm{~Hz}$ ), during tibial stimulation. Twenty-one volunteers were subjected to $5 \mathrm{~Hz}$ stimulation by current pulses of $0.2 \mathrm{~ms}$ duration and the minimum intensity to provoke involuntary twitch. EEG signals without (spontaneously) and during stimulation were re co rded at primary somatosensory area. A time-frequency analysis indicated the effect of the stimulus artifact in the somatosensory evoked potential (SEP) frequencies up to $5 \mathrm{~ms}$ after the stimulus. The oscillations up to $100 \mathrm{~Hz}$ presented the highest relative power contribution (approximately $99 \%$ ) for the SEP and showed diff e rence $(p<0.01)$ from the f requencies of the spontaneously EEG average. More over, the range 30-58 Hz was identified as the band with the highest contribution for the tibial SEP morphology $(p<0.0001)$.
\end{abstract}

KEY WORDS: gamma oscillations, somatosensory evoked potential, tibial nerve, time-frequency analysis.

\section{Oscilações de baixa freqüência no potencial evocado somato-sensitivo do nervo tibial humano}

RESUMO - Oscilações da atividade elétrica cerebral têm sido associadas a funções sensoriais, de percepção e de cognição. O presente estudo objetiva investigar as oscilações de baixa freqüência, em particular da banda gama (30-110 Hz), durante estimulação do nervo tibial. Vinte e um voluntários foram estimulados com pulsos de corrente de $0,2 \mathrm{~ms}$, freqüência de $5 \mathrm{~Hz}$ e intensidade mínima para produzir o movimento involuntário dos músculos intrínsecos do pé. Sinais EEG espontâneo e durante estimulação foramregistrados na área somato-sensitiva primária. A análise tempo-freqüência indicou o efeito do artefato ao estímulo na banda de freqüência do potencial evocado somato-sensitivo (PESS) até aproximadamente 5 ms pósestímulo. As oscilações até $100 \mathrm{~Hz}$ apresentaram maior contribuição relativa de potência ao PESS (aproximadamente $99 \%)$ e se mostraram significativamente diferentes $(p<0,01)$ das freqüências da média coerente do EEG espontâneo. Além disso, a banda 30-58 Hz foi identificada como a de maior contribuição à morfologia do PESS do nervo tibial $(p<0,0001)$.

PALAVRAS-CHAVE: oscilações gama, potencial evocado somato-sensitivo, nervo tibial, análise tempo-freqüência.

Oscillatoryneural activity has been investigated at cellular level', in human electroencephalogram $(\mathrm{EEG})^{2}$ and magnetoencephalogram (MEG) ${ }^{3,4}$. Such oscillations have been related to sensory processing ${ }^{5,6}$ and perceptual-cognitive functions ${ }^{7,8}$. Various functional mechanisms have been associated with this phenomenon as: memory ${ }^{9}$, attention ${ }^{10}$, object re p resentation ${ }^{11}$ and pain perception ${ }^{12}$. Thus, according with Basar et al. ${ }^{6}$, the brain oscillations should explain the binding problem between the sensory processing and cognitive functions.

EEG recordings have revealed the existence of transient frequency oscillations in diff e rent bands, mainly in the gamma band $(30-110 \mathrm{~Hz})$. Several authors ${ }^{6,7,13,14}$ have pointed out that if this oscillations appear with the same latency and phase after each stimulus, then it is considered evoked activity. Moreover, different authors ${ }^{2,10,15,16}$ reported that these oscillations build up the morphology of the evoked potential (time average synchronized with the stimulus).

Evoked oscillations of high frequency (300-900 $\mathrm{Hz}$ ) during somatosensory stimulation of tibial nerve have been investigated by several authors ${ }^{17-20}$. The

\footnotetext{
${ }^{1}$ Associate Professor, Biomedical Engineering Group (GENEBIO) - Electrical Department - Federal University of Minas Gerais (UFMG), Belo Horizonte MG, Brazil; ${ }^{2}$ Professor, Biomedical Engineering Program - COPPE - Federal University of Rio de Janeiro (UFRJ), Rio de Janeiro RJ, Brazil. Financial support by Brazilian Agencies CNPq, CAPES and FAPEMIG.
}

Received 12 August 2005, received in final form 9 December 2005. Accepted 8 February 2006.

Dr. Carlos Julio Tierra-Criollo - Electrical Department - Federal University of Minas Gerais (UFMG) - Av. Antônio Carlos 6627 31270-010 Belo Horizonte MG - Brasil. E-mail: carjulio@cpdee.ufmg.br 
p resent study aims at investigating the brain oscillations in the frequency band up to $300 \mathrm{~Hz}$, particularly within the gamma band, during stimulation of the right tibial nerve. In addition, the effect of the stimulus artifact in the evoked response is also estimated, both in time and frequency domain. For such investigation, the spectral analysis and statistical test will be applied to the somatosensory evoked potential (SEP).

\section{METHOD}

Subjects - EEG signals without (spontaneously) and during electrical stimulation of the right posterior tibial nerve at the ankle were recorded from twenty one volunteers (18 male), aged between 18 and 42 years old, and height from 1.55 to $1.86 \mathrm{~m}$ (Table 1), with no symptoms of neurological pathology and with normal SEP. The eyes of the subjects were closed during a state of relaxed wakefulness throughout the experiment. The SEP's were visually checked by an experienced clinician. The local ethics committee (CEPHUCFF/UFRJ) approved this research.

Stimuli - The volunteers were subjected to periodic stimulation using a Sapphire" 4ME (Medelec, UK) Evoked Potential System and two $\mathrm{Ag} / \mathrm{AgCl}$ electrodes (distance $3 \mathrm{~cm}$ ). A ground electrode was placed at popliteal fossa. Current pulses of $0.2 \mathrm{~ms}$ duration and minimum intensity (5-24 mA, Table 1) to provoke the involuntary twitch (motor threshold $-M T$ ) of the intrinsic foot muscle supplied by the tibial nerve were employed. The stimulus rate was $5 \mathrm{~Hz}$, for which clearly defined evoked responses are expected ${ }^{21}$. Two sessions of 1024 stimuli $\left(M T_{1}\right.$ e $\left.M T_{2}\right)$ we re carried out, with at least one minute interval between stimulation periods.

EEG signals - The recording electrodes $(\mathrm{Ag} / \mathrm{AgCl})$ were positioned at $\mathrm{Cz}^{\prime}$ ( $2 \mathrm{~cm}$ behind the $\mathrm{Cz}$ electrode position of the 10-20 International System), with the re $f$ e rence at $\mathrm{Fpz}^{\prime}$ (midway between Fpz and Fz), as is usual for somatosensory evoked potentials ${ }^{22}$. The electrode impedance kept below $2 \mathrm{k} \Omega$ and the bandpass filter of the Evoked Potential System was set at $10 \mathrm{~Hz}$ to $2 \mathrm{kHz}$. The raw EEG signal from the analog output of the Sapphire" was digitized at a sampling rate of $f_{s=5} \mathrm{kHz}$ and a resolution of 12 bits (DAQPad1200, National Instruments, USA), using software developed in LabVIEW (Version 5.01, National Instruments, USA). The trigger signal, showing the instant of each stimulus, was also acquired. The environmental temperature was controlled nearly $25^{\circ} \mathrm{C}$, that is $25.1 \pm 0.6^{\circ} \mathrm{C}$.

Somatosensory evoked potentials (SEP) - The estimated SEP by coherence mean technique (time average syn$c h$ ronized with the stimulus) of $M=800$ epochs (epoch is a period between two stimuli) resulted in improvement of $\sqrt{800}$ in the signal-noise relation (amplitude) from spontaneously EEG. Also, a better quality of the SEP was obtained by using the algorithm for automatic artifact rejection described in previous work ${ }^{23}$.

Spectral analysis - Denoting the SEP as the temporal sequence of $L$ data samples $\{s(n), n=0,1,2, \ldots, L-1\}$, its power spectral was obtained by ${ }^{24}$ :

$P_{s}\left(f_{m}\right)=\frac{T}{L}|S[m]|^{2}=\frac{T}{L}\left|\sum_{D m 0}^{T} s(n) e^{-1200 m i L}\right|^{2}$

where $T=1 / f s, f_{m}=m / L T, m=0,1 \ldots, L-1$ and $S[m]$ is the $m$ coefficient of discrete-time Fourier Transform - calculated by Fast Fourier Transformalgorithm (FFT) - that corresponds to $f_{m}$ frequency. Thus, $P_{s}\left(f_{m}\right)$ is the energy contribution of the $f_{m}$ frequency for SEP morphology.

Stimulation artifact - The electrical stimulation of the tibial nerve produces a transient signal of high amplitude

Table 1. Short latency SEP components at CZ'-Fpz' derivation of the 21 volunteers (identified by an experienced clinician). $P$ and $N$ rep resents the valley and peak latencies corresponding to P37 and N45 components, respectively.

\begin{tabular}{|c|c|c|c|c|}
\hline & Mean & $\begin{array}{l}\text { Standard } \\
\text { deviation }\end{array}$ & Maximum & Minimum \\
\hline Age (years) & 26.4 & \pm 5.2 & 42 & 18 \\
\hline Height (m) & 1.72 & \pm 0.08 & 1.86 & 1.55 \\
\hline \multicolumn{5}{|c|}{ Intensity of motor threshold (MT) } \\
\hline Current (mA) & 13.5 & \pm 4.5 & 24 & 5 \\
\hline \multicolumn{5}{|c|}{ First stimulation session $\left(M T_{1}\right)$} \\
\hline$P(\mathrm{~ms})$ & 37.9 & \pm 2.8 & 44.3 & 32.9 \\
\hline $\mathrm{N}(\mathrm{ms})$ & 46.8 & \pm 3.0 & 53.2 & 42 \\
\hline \multicolumn{5}{|c|}{ Repetition session $\left(M T_{2}\right)$} \\
\hline$P(\mathrm{~ms})$ & 38.1 & \pm 2.7 & 44.3 & 34.3 \\
\hline$N(\mathrm{~ms})$ & 46.9 & \pm 2.5 & 52.7 & 42 \\
\hline
\end{tabular}




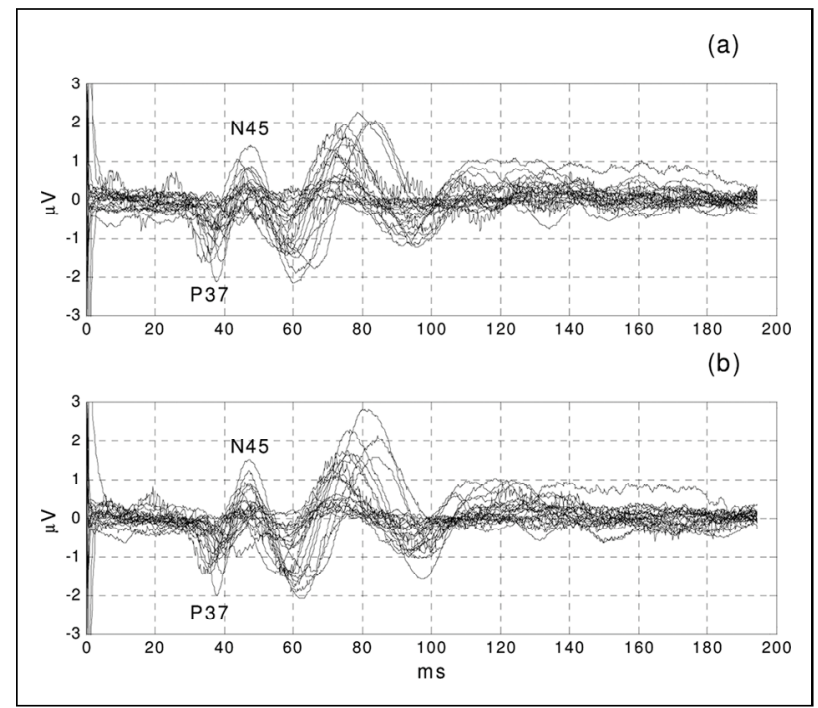

Fig 1. SEP (CZ'-Fpz' derivation) of 21 volunteers with $M=800$ epochs during (a) $M T_{1}$ and (b) $M T_{2}$ stimulation sessions.

and short time duration (stimulus artifact) synchronous and immediately after the stimulus. Thus, the effect of this art ifact in the SEP was estimated by using a time-frequency analysis.

\section{RESULTS}

The SEP of the Cz'-Fpz' derivation (Fig 1) shows, as expected, the principal morphological characteristics P37 and N45 ${ }^{21,22}$. The data in the Table 1 evidence the similarity of the SEP's, during $M T_{1}$ and $M T_{2}$ stimulation sessions.

The time-frequency analysis of the SEP (Fig 2) indicated that the stimulus artifact contributes with high energy in the whole frequency band $(0-2 \mathrm{kHz})$ up to $2 \mathrm{~ms}$ after the stimulus (Figs $2 \mathrm{~B}$ and $2 \mathrm{C}$ ). Then, the energy of the stimulus artifact decreases approximately up to $1 \mathrm{kHz}$ and latency of $5 \mathrm{~ms}$. The statistical comparison (non-parametric Wilcoxon test for paired data) between SEP and spontaneously EEG average (EEGa) spectrograms of the 21 volunteers also indicated a diff e rence $(p<0.05)$ up to $5 \mathrm{~ms}$ after the stimulus. Furtherm ore, notice the increment of the power contribution (approximately up to $1 \mathrm{kHz}$ ) in the latencies P37 and N45 in comparison with the EEGa (Fig 2B).

The power spectrum of a rectangular window (5-195 ms) of a SEP during $M T_{1}$ (Fig 3) shows the energy concentrated up to $100 \mathrm{~Hz}(99 \%)$. On the other hand, the EEGa spectrum shows relative contributions of power in higher frequencies, approximately up to $1 \mathrm{kHz}(99 \%)$. Similar observations were carried out for all the volunteers and during $M T_{2}$.

The frequencies corresponding to the maximum

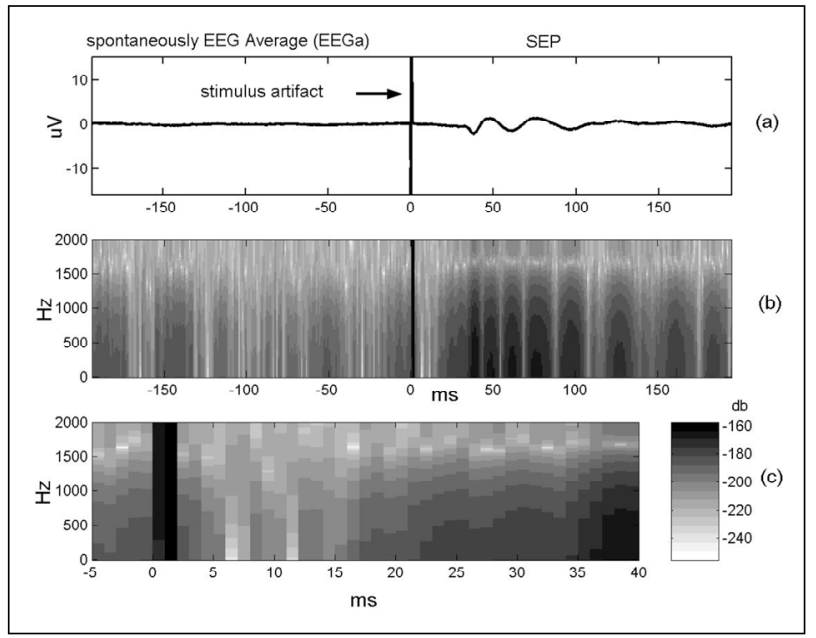

Fig 2. (a) Spontaneously EEG average (EEGa, -194 to $0 \mathrm{~ms}$ ) and SEP during $M T_{1}$ (0 to $194 \mathrm{~ms}$ ), for the volunteer \#21 and $M=800$ epochs. (b) Spectrogram using a $1 \mathrm{~ms} \mathrm{Hann}$ window, without overlapping but with zero padding, resulting in a spec tral resolution of $10 \mathrm{~Hz}$. (c) zoom of (b).

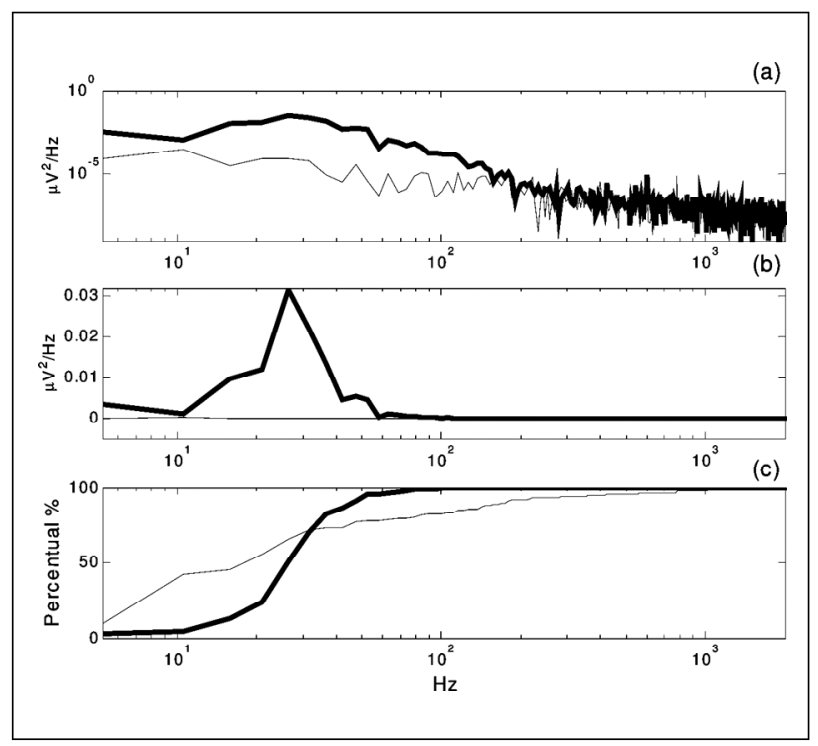

Fig 3. Power spectra of the SEP ( $M=800$ epochs) during $M T_{1}$ (thick line) and the EEGa ( $M=800$ epochs) just before the stim ulation (thin line) of the volunteer \#21. The power spectra were obtained using a rectangular window of 190 ms duration (spec tral resolution of $5.3 \mathrm{~Hz}$ ), from 5 to $195 \mathrm{~ms}$ latencies for the SEP. (a) logarithmic scale, (b) linear scale, and (c) percent of the relative accumulated energy.

peak of the SEP spectrum, during $M T_{1}$ stimulation, in the 21 volunteers (Table 2 ) indicate that the band from 5 to $58 \mathrm{~Hz}$, with median equal to $21 \mathrm{~Hz}$ (Table $3)$, contributes with the most power for the SEP morphology. On the other hand, the EEGa spectrum contains the maximm peaks in the $5-780 \mathrm{~Hz}$ band, with median equal to $10 \mathrm{~Hz}$. The Wilcoxon test (Table 3) 
Table 2. Frequency corresponding to the maximum peak of the SEP spectrum during $M T^{\prime}$ stimulation in the 21 volunteers (in parentheses values for EEGa spectrum).

\begin{tabular}{lccccc}
\hline \multicolumn{5}{c}{ Frequency $(\mathrm{Hz})$} \\
\hline$\# 1$ & $10.6(21.1)$ & $\# 8$ & $10.6(10.6)$ & $\# 15$ & $15.8(10.6)$ \\
$\# 2$ & $15.8(780.6)$ & $\# 9$ & $31.7(10.6)$ & $\# 16$ & $58.0(10.6)$ \\
$\# 3$ & $31.7(26.4)$ & $\# 10$ & $31.7(10.6)$ & $\# 17$ & $36.9(10.6)$ \\
$\# 4$ & $5.3(10.6)$ & $\# 11$ & $5.3(5.3)$ & $\# 18$ & $15.8(10.6)$ \\
$\# 5$ & $31.7(5.3)$ & $\# 12$ & $15.8(10.6)$ & $\# 19$ & $21.1(10.6)$ \\
$\# 6$ & $15.8(5.3)$ & $\# 13$ & $15.8(31.6)$ & $\# 20$ & $26.4(10.6)$ \\
$\# 7$ & $31.7(10.6)$ & $\# 14$ & $31.7(21.1)$ & $\# 21$ & $26.4(10.6)$ \\
\hline
\end{tabular}

Table 3. Statistics for frequency corresponding to the maximum peak of the SEP spectrum (in parentheses values for EEGa spec trum just before stimulation)

\begin{tabular}{lcc}
\hline & $M T_{1}$ & $M T_{2}$ \\
\hline Median (Hz) & $21.1(10.6)$ & $15.8(10.6)$ \\
Minimum (Hz) & $5.3(5.3)$ & $10.6(5.3)$ \\
Maximum (Hz) & $58.0(780.6)$ & $31.7(780.6)$ \\
p (Wilcoxon) & 0.03 & 0.19 \\
\hline
\end{tabular}

was applied to these frequency bands and it indicated a significant diffe rence between SEP and EEGa for $M T_{1}(\mathrm{p}=0.03)$, although it was not the case for $M T_{2}$ $(p=0.19)$. Thus, alternatively, the Wilcoxon test was applied to each frequency component of the SEP and EEGa spectra in the 21 volunteers. A significant difference $(p<0.01)$ was found in low frequencies, approximately up to $100 \mathrm{~Hz}$ (Fig 4), being the range from 30 to $58 \mathrm{~Hz}$ the band with most significance difference $(p<0.0001)$. This result was similar for $M T_{2}$ stimulation session.

\section{DISCUSSION}

The time-frequency analysis of the tibial SEP indicated a significant effect $(p<0.05)$ of the stimulus artifact in the frequency components of the SEP appro $x$ imately up to $5 \mathrm{~ms}$ after the stimulus. In previous studies, the presence of this artifact in the tibial SEP was consideredup to $3 \mathrm{~ms}^{25}, 5 \mathrm{~ms}^{26}$, and $10 \mathrm{~ms}^{27}$. Erwin et al. ${ }^{28}$ reported that this artifact can be avoided by beginning the analysis from 1 to $5 \mathrm{~ms}$ after the stimulus, which depend on the stimulated nerve. Therefore, it is not still established the initial instant for analysis of the tibial SEP. Thus, the use of the timefrequency analysis, together with the statistical infer-

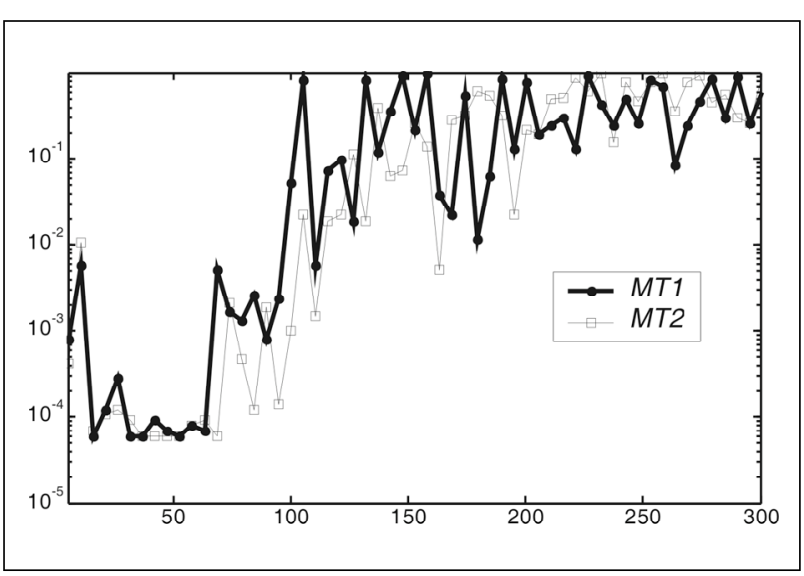

Fig 4. p-value of statistical comparison (Wilcoxon test for paired data) between each frequency component of the SEP spectrum and EEGa spectrum just before stimulation. $M T_{1}$ (thick line) and $M T_{2}$ (thin line) sessions.

ence, it can contribute to determine the stimulation artifact duration, although this procedure cannot guarantee the identification of the long and slow components of this artifact, because they can be overlapped on the physiologic response.

The frequency of the maximum power of the SEP spectrum, for the group of 21 volunteers, indicated the band up to $58 \mathrm{~Hz}$ as the best to identify the evoked response to the posterior tibial stimulation. Although this procedure is similar to the adopted by Basar et al. ${ }^{14}$, this band was not statistically different $\left(p=0.19\right.$ ) to the EEGa band (up to $780 \mathrm{~Hz}$ ) during $M T_{2}$ stimulation session. Such evidence suggests that the spectral analysis alone is not the most appropriate procedure to diff e rentiate bands between the SEP and EEGa. The Wilcoxon test applied to each frequency component of the SEP and EEGa spectra shows significant diffe rence $(p<0.01)$ up to $100 \mathrm{~Hz}$ for both $M T_{1}$ and $M T_{2}$ stimulation sessions. This finding suggests that there is relevant information in other frequency bands than the 13-55 $\mathrm{Hz}$ range used by Gobbelé et al. ${ }^{10}$ in their study of the relation between the sensory process (tibial and median nerves) and the attention. However, it is worth to point out that the frequency components with higher contribution to the SEP morphology are within the range from 30 to $58 \mathrm{~Hz}$ (significance level, $\mathrm{p}<0.0001$ ). Nakano and Hashimoto ${ }^{19}$ have also found that the energy of the tibial SEP spectrum is concentrated in the range 40-60 $\mathrm{Hz}$, although distributed from 20 to $300 \mathrm{~Hz}$. By stimulating other nerves, Noss et al. ${ }^{29}$ reported the low f requencies (up to $100 \mathrm{~Hz}$ ) as those with higher contribution to the somatosensory response in the human being. 
Tibial somatosensory evoked potential is now being broadly introduced into clinical practice and intraoperative monitoring ${ }^{30,31}$. With this aim, normal values of SEP parameters are essential for a reliable application. The effect of subject height, age and gender on latency, inter-peak interval and amplitude characteristics of tibial SEP was recently investigat$\mathrm{ed}^{31}$. In this kind of studies, the time-frequency analysis here applied, as well as the frequency components that better characterize the SEP is fundamental for investigating the brain oscillations due somatosensory stimulation. Moreover, these frequencies could be considered for somatosensory evoked potential intraoperative monitoring and clinical applications.

Acknowledgments - The authors are grateful to Dr. Eduardo Zaeyen for his help in EEG acquisitions.

\section{REFERENCES}

1. Steriade M. Cellular substrates of brain rhythms. In Niedermeyer E, Lopes da Silva FH (eds). Electroencephalograpy: basic principles, clinical applications, and related fields. 4 Ed. New York: Williams \& Wilkins, 1998:28-75.

2. Basar-Eroglu C, Demiralp T. Event-related theta oscillations: an integrative and comparative approach in the human and animal brain. Int J Psychophysiol 2001;39:167-195.

3. Della Penna S, Torquati K, Pizzella V, et al. Temporal dynamics of alpha and beta rhythms in human SI and SII after galvanic median nerve stimulation: a MEG study. Neuroimage 2004;22:1438-1446.

4. Lopez L, Sannita WG. Magnetically recorded oscillatory responses to luminance stimulation in man. Electroencephalogr Clin Neurophysiol 1997;104:91-95.

5. Sannita WG. Stimulus-specific oscillatory responses of the brain: a time/ frequency-related coding process. Clin Neurophysiol 2000;111:565-583.

6. Basar E, Basar- E roglu C, Karakas S, Schürmann M. Oscillatory brain theory: a new trend in neuroscience. IEEE Eng Med Biol Mag 1999;18: 56-66.

7. Herrmann CS, Munk MHJ, Engel AK. Cognitive functions of gammaband activity: memory match and utilization. Trends Cogn Sci 2004; 8:347-355

8. Basar E, Basar-Eroglu C, Karakas S, Schürmann M. Gamma, alpha, delta, and theta oscillations govern cognitive process. Int J Psychophysiol 2001;39:241-248.

9. Düzel E, Habib R, Schott B, et al. A multivariate, spatiotemporal analysis of electromagnetic time-frequency data of recognition memory. Neuroimage 2003;18:185-197.

10. Gobbelé R, Waberski TD, Schmitz S, Sturm W, Buchner H. Spatial direction of attention enhances right hemispheric event-related gammaband synchronization in humans. Neurosci Lett 2002;327:57-60.

11. Kaiser J, Bühler M, Lutzenberger W. Magnetoencephalographic gamma-band responses to illusory triangles in humans. Neuroimage 2004; 23:551-560.

12. Pascalis VD, Cacace I. Pain perception, obstructive imagery and phaseordered gamma oscillations. Int J Psychophysiol 2005;56:157-169.
13. Karakas S, Basar E. Early gamma response is sensory in origin: a conclusion based on cross-comparison of results from multiple experimental paradigms. Int J Psychophysiol 1998;31:13-31.

14. Basar E, Basar-Eroglu C, Demiralp T, Schürmann M. Time and frequency analysis of the brain's distributed gamma-band system. IEEE Eng Med Biol Mag 1995;14:400-410.

15. Karakas S, Basar-Eroglu C, Ozesmi Ç, Kafadar H. Gamma response of the brain: a multifunctional oscillation that represents botom-up with top-down processing. Int J Psychophysiol 2001;39:137-150.

16. Rossini PM, Cracco RQ, Cracco JB, House WJ. Short latency somatosensory evoked potentials to peroneal nerve stimulation: scalp topography and the effect of different frequency filters. Electroencephalogr Clin Neurophysiol 1981;52:540-552.

17. Inoue K, Hashimoto I, Nakamura S. High-frequency oscillations in human posterior tibial somatosensory evoked potentials are enhancend in patients with Parkinson's disease and multiple system atrophy. Neurosci Lett 2001;297:89-92.

18. Maegaki Y, Najm I, Terada K, et al. Somatosensory evoked high-frequency oscillations re co rded directly from the human cerebral cortex. Clin Neurophysiol 2000;111:1916-1926.

19. Nakano S, Hashimoto I. Comparison of somatosensory evoked high$\mathrm{f}$ requency oscillations after posterior tibial and median nerve stimulation. Clin Neurophysiol 1999;110:1948-1952.

20. Sakuma K, Sekihara K, Hashimoto I. Neural source estimation from a time-frequency component of somatic evoked high-frequency magnetic oscillations to posterior tibial nerve stimulation. Clin Neurophysiol 1999;110:1585-1588.

21. Chiappa KH. Evoked potentials in clinical medicine, $3^{\text {rd }}$ Ed. Philadelphia: Lippincott-Raven, 1997.

22. Misulis KE. Espehlmann's evoked potential primer: visual, auditory and somatosensory evoked potentials in clinical diagnosis, $2^{\text {nd }} \mathrm{Ed}$. Boston: Butterworth-Heinemann, 1994.

23. Simpson DM, Tierra-Criollo CJ, Leite RT, Zayen EJB, Infantosi AFC. Objective response detection in an electroencephalogram during somatosensory stimulation. Ann Biomed Eng 2000;28:691-698.

24. Marple SL. Digital spectral analysis with applications. Englewood Cliffs-New Jersey: Prentice-Hall, 1987.

25. Kakigi R, Shibasaki H. Scalp topography of the short latency somatosensory evoked potentials following posterior tibial nerve stimulation in man. Electroencephalogr Clin Neurophysiol 1983;56:430-437.

26. Kakigi R. The effect of aging on somatosensory evoked potentials following stimulation of the posterior tibial nerve in man. Electroencephalogr Clin Neurophysiol 1987;68:277-286.

27. Pelosi L, Cracco JB, Cracco RQ. Conduction characteristics of somatosensory evoked potentials to peroneal, tibial and sural nerve stimulation in man. Elecencephalogr Clin Neurophysiol 1987;68:287-294.

28. Erwin CW, Rozear MP, Radtke RA, Erwin AC. Somatosensory evoked potentials and surgical monitoring. In Niedermeyer E, Lopes da Silva FH (eds). Electroencephalograpy: basic principles, dinical applications, and related fields, $3^{\text {rd }}$ Ed. Baltimore: Williams \&Wilkins, 1993:957-974

29. Noss RS, Boles CD, Yingling CD. Steady-state analysis of somatosensory evoked potentials. Electroencephalogr Clin Neurophysiol 1996;100: 453-461.

30. MacDonald DB, Stigsby B, Al Zayed Z. A comparison between derivation optimization and $\mathrm{Cz}-\mathrm{FPz}$ for posterior tibial P37 somatosensory evoked potential intraoperative monitoring. Clin Neurophysiol 2004; 115:1925-1930.

31. Miura T, Sonoo M, Shimizu T. Establishment of standard values for the latency, interval and amplitude parameters of tibial nerve somatosensory evoked potentials (SEPs). Clin Neurophysiol 2003;114:1367-1378. 